\title{
LONG-TERM MONITORING OF THE IMPACT OF MINING OPERATIONS ON THE GROUND SURFACE AT THE REGIONAL SCALE BASED ON THE INSAR-SBAS TECHNIQUE, THE UPPER SILESIAN COAL BASIN (POLAND). CASE STUDY
}

\author{
Anna KOPEĆ *, Natalia BUGAJSKA, Wojciech MILCZAREK and Dariusz GEĄBICKI \\ Wroclaw University of Science and Technology, Faculty of Geoengineering, Mining and Geology, Department of Geodesy and
} Geoinformatics, Wybrzeze Wyspianskiego 27, 50-370 Wroclaw, Poland

*Corresponding author's e-mail: anna.kopec@pwr.edu.pl

\begin{tabular}{|c|c|}
\hline ARTICLE INFO & ABSTRACT \\
\hline Article history: & \multirow{9}{*}{$\begin{array}{l}\text { Underground mining activity in the region of the Upper Silesian Coal Basin (USCB) results in } \\
\text { ground displacements scattered on a large area. Both the locations and the velocities of the } \\
\text { displacements depend on many factors, such as the current location of the mining front, the mining } \\
\text { depth and system, as well as geological conditions. Although SAR interferometry techniques allow } \\
\text { the monitoring of such ground displacements, in a regional scale (as is the case of the USCB) SAR } \\
\text { images must be appropriately processed (from a number of frames and swaths), and this is the } \\
\text { problem addressed in this article. The implementation of algorithms for analyzing time series } \\
\text { allows observations of displacements in both time and space. The authors also analyze the } \\
\text { influence of mining operations on the road infrastructure and mining waste heaps located in the } \\
\text { area and investigate the potential for the monitoring of secondary influence (due to induced seismic } \\
\text { tremors). As a result of these investigations, the article presents the quality of the InSAR-SBAS } \\
\text { data and the potential for their employment in the measurements. }\end{array}$} \\
\hline Received 27 September 2021 & \\
\hline Accepted 12 December 2021 & \\
\hline Available online 21 December 2021 & \\
\hline Keywords: & \\
\hline InSAR & \\
\hline Subsidence & \\
\hline Regional scale monitoring & \\
\hline Sentinel 1A/1B & \\
\hline
\end{tabular}

\section{INTRODUCTION}

For more than twenty years, SAR interferometry (InSAR) has been successfully used in the observations of ground surface displacements, also those of anthropogenic origin. Mining activity is one of the most important anthropogenic factors behind such ground surface deformations. SAR differential interferometry has been employed in monitoring areas of underground mining activity since the end of the 20th century (Carnec et al., 1996; Carnec and Delacourt, 2000). The development of InSAR data processing techniques, belonging to both the persistent scatterer (Permanent/Persistent Scatter InSAR, PSI) (Ferretti et al., 2000, 2001) or the distributed (the Small BAseline Subset, SBAS) (Berardino et al., 2002) families, allowed the limiting of the influence of decorrelation and an observation of deformations in time (Kircher et al., 2003; Colesanti et al., 2005; Baek et al., 2008).

Ground surface displacements are observed regardless of the mining method (underground, surface or borehole). The impact of mining operations is manifested on the surface both by subsidence troughs which are a direct result related to the formation of empty spaces in the rock mass and, indirectly, by large-area subsidence due to rock mass drainage. These manifestations are long-time processes and may depend on a number of factors, such as the mining method (the mining system and depth) and the geological conditions (Kratzsch, 1983).
Ground surface displacements may be observed even many years after the mining operation was closed (Blachowski et al., 2019). For these reasons, the implementation of time series-based InSAR techniques allows observations of the long-term effects of mining activity on the ground surface in time and over a large area. However, according to $\mathrm{Ng}$ et al. (2017), significant ground displacement increments, observed for example in the case of longwall mining techniques, may cause phase unwrapping problems. In the case of the SBAS algorithm, which is used in the processing of a great number of interferograms, improperly unwrapped phase in individual interferograms may produce underestimated results, especially in the central part of the subsidence trough.

The tests were performed for the area of the Upper Silesian Coal Basin (USCB) (Fig. 1), where hard coal is mined underground mainly with the use of the longwall system. The USCB region covers a fragment of southern Poland and the OstravaKarviná region in the Czech Republic. In order to follow ground surface deformations, the authors used SAR images from the Sentinel-1 A/B satellites, for the period of $2014-2020$. The article also presents the results of SBAS calculations performed for the data from several swaths and frames. In effect, the result is uniform for the entire USCB region. The proposed approach allows the impact of underground mining activity to be monitored on a regional scale and for a long period of time. The article places a particular 
emphasis on the fact that the SBAS technique is not a classic measurement method used in geodesy - it discusses the advantages and disadvantages of this method in relation to the monitoring of ground surface displacements due to mining activity.

\section{MATERIAL AND METHODS THE SBAS TECHNIQUE}

In satellite interferometry, the coherence value is of key importance for the quality of the results obtained with the use of the time-series method. This value depends primarily on the value of the temporal and spatial base between a particular pair of radar images. The smaller base, the better coherence, and thus the better the quality of the identified phase of the interferometric signal. This relationship is used in the SBAS calculations of displacement time series. Unlike in the case of the PSI technique, in which the interferograms in the radar data set are formed with respect to a single master image, in the SBAS method the interferograms are constructed from radar images following the "each-to-each" principle, so that the resulting set of interferograms has the lowest values of spatial and temporal bases. After the interferograms are constructed and unwrapped, the next step is to choose pixels which have the lowest spatial variability. These pixels serve to calculate displacement in time by solving a system of equations.

For a single interferogram, the $\pi$ limit of the phase value corresponds to a displacement of $\lambda / 4$. If the difference value of the interferogram phase due to the displacement is greater than $\pi$, then the actual displacement value may be wrongly identified after unwrapping (Hanssen, 2001). The spatial gradient of displacement is also important, the smaller the spatial extent of displacement, the smaller the maximum displacement value detectable by InSAR techniques. The maximum detectable deformation gradient mainly depends on the spatial resolution of the SAR images, the electromagnetic wavelength and the revisit period (Zhang et al., 2020). Further aspect is the decorrelation-induced coherence losses due to, e.g., vegetation, as well as the aforementioned large deformation gradients (Ma et al., 2016; Yang et al., 2017). A phase value ambiguity leading to unwrapping errors may cause a mismeasurement of the displacement value of individual interferograms, and consequently also for the SBAS algorithm processing results.

Apart from the above-presented properties, the SBAS time-series method allows the reduction of atmospheric and orbital errors (as these errors are spatially correlated), as well as the estimation of the DEM error. The method also allows a greater number of "persistent" pixels to be detected, as a single "dominant" scatterer is not required, unlike in the PSI method. As a result, pixels referred to as distributed scatterers are also detected, allowing application of the SBAS technique also in non-urbanized areas.

Over the years, a substantial number of algorithms have been developed for the processing of time series with the use of small baseline methods, e.g. SBAS (Berardino et al., 2002), NSBAS (Doin et al., 2011), coherence-based SBAS (Tong and Schmidt, 2016) or LiCSBAS (Morishita et al., 2020).

\section{THE RESEARCH AREA AND THE USE OF SAR TO-} DATE IN THE USCB REGION

The analyzed test area (the USCB) is located in the South of Poland, in the Lower Silesian and Smaller Poland Voivod ships, as well as in the OstravaKarviná region in the Czech Republic. It is the largest coal field in Poland and all active Polish hard coal mines except one (the Bogdanka mine in the Lublin Coal Basin) are located within its area. The total surface area of the USCB is approximately $7250 \mathrm{~km}^{2}$, of which ca. $5650 \mathrm{~km}^{2}$ is located within the borders of Poland (Jureczka and Nowak, 2016). As per Dec. 31, 2018, the USCB has 144 coal deposits, 43 of them being actively mined (Fig. 1). The total balance resources exceed 49 billion metric tons, which is more than $80 \%$ of the documented balance deposits of hard coal in Poland. Power coal and coking coal, the latter being extracted mainly in the western part of the basin, are of the greatest economic value (Szaflucki et al., 2020). The presence of rich hard coal deposits in Carboniferous formations facilitated the development of three relatively undiversified industrial regions in the USCB: the Upper Silesian Industrial Region (Polish: Górnośląski Okręg Przemysłowy, USIR), the Rybnik Coal Region (Polish: Rybnicki Okręg Węglowy, RCR) and the Ostrava-Karviná Industrial Region (Czech: Ostravsko-Karvinský Revír, OKIR).

The dominant mining system employed in the USCB is the longwall retreat system, which has high mining concentration owing to mechanical extraction processes. Average mining depth at USCB is approximately $760 \mathrm{~m}$, and in some cases it exceeds $1200 \mathrm{~m}$ (Burtan, 2016). The mining and geological conditions are complicated, and result from the presence of tectonic disturbances (mainly faults), sedimentation disturbances (irregularities in the formation of beds), old workings (multi-bed deposits, including remnants of metal ore extraction in the northern part of the USCB), the need to extract from residual areas and from greater depths (Zorychta and Burtan, 2008). Moreover, significant daily progress of the mining face leads to the formation of large empty spaces in the rock mass. These empty spaces are gradually reduced by the gravity acting due to the layers located above. The rocks are directly above the empty space collapse and fracture, while the successive layers above subside. As the stresses in the rock mass become balanced, ground surface deformations occur, and these are frequently accompanied by seismic events of relatively small intensity. The character of the deformations (continuous or non-continuous) depends among other things from (Kaszowska, 2007):

- the mining depth,

- the thickness of the worked space, 


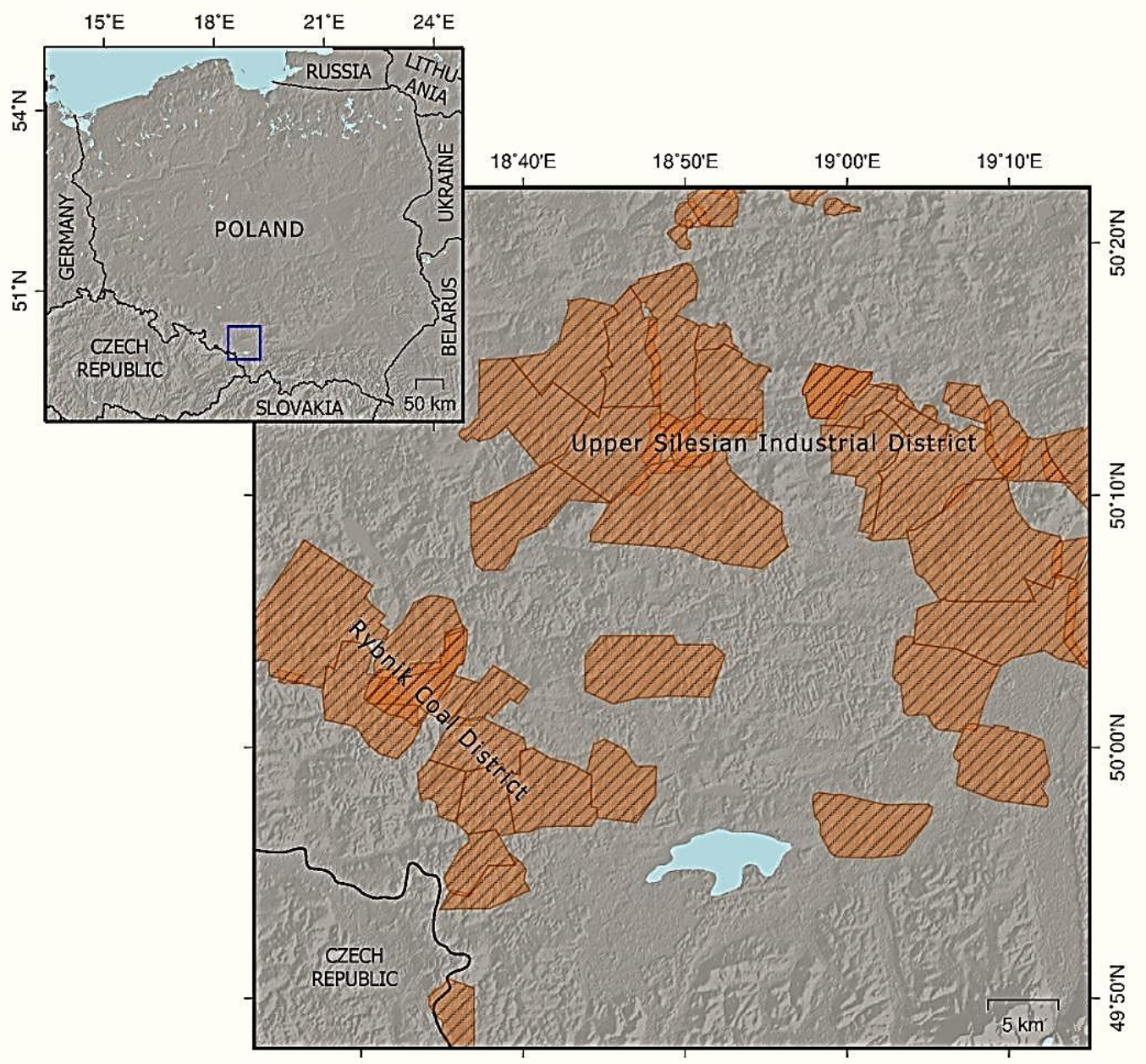

Fig. 1 Location of the study area, the blue line represents the location of the area in Poland and orange dashed areas indicate mining areas of active mines on the territory of Poland.

- the method for filling the post-mining voids,

- the progress speed of the mining face,

- the geological structure of the layers above the void.

In the USCB, the displacement increment speeds are observed at a level from several up to a maximum of more than ten millimeters per day (Kowalski, 2020). This fact means that over a period of one year a subsidence increment may exceed $1 \mathrm{~m}$. From the perspective of InSAR-based displacement analysis, such displacement dynamics may be challenging.

The first studies on the use of InSAR measurement techniques in the aspect of investigating ground displacements caused by mining activities in the GZW area were carried out at the end of the 1990s by Perski $(1998,1999)$. Calculations with the DInSAR technique were performed using data from the ERS $1 / 2$ satellites. In the following years a group of researchers from the Polish Geological Institute also conducted studies on the dynamics of the ground surface in the GZW area based on SAR data (Graniczny et al., 2015). In these papers, data from different SAR platforms (ERS 1/2, Envisat, ALOS PALSAR and TerraSAR-X) were used, which allowed the observation of displacements in the GZW area from 1992 to 2011 using the PSI technique. Further significant publications on the monitoring of displacements induced by mining activities in the GZW region based on InSAR techniques are related to the release of data from the Sentinel-1 mission in 2014. Krawczyk and Grzybek (2018) and Sopata et al. (2020) investigated the manifestation of secondary influences (resulting from induced mining tremors) on the ground surface. Pawłuszek-Filipiak and Borkowski (2020 a,b) conducted research on the integration of the DInSAR technique with PSI and SBAS techniques for the monitoring of mining impacts on the ground surface in the GZW area.

\section{DATA PROCESSING}

Long-term displacements were identified on the basis of data from a descending path (no. 51) and an ascending path (no. 175). The calculations of the satellite radar data were based on the coherence-based SBAS method (Tong and Schmidt, 2016) with the enhanced spectral diversity (ESD) algorithm. The data was processed with GMTSAR (Sandwell et al., 2011) with additional post processing using GMT (Wessel and Smith, 2013). Phase unwrapping was performed 
Table 1 Summary of the total number of available Sentinel 1 data and the number of processed raw data to the extent of the analyzed area.

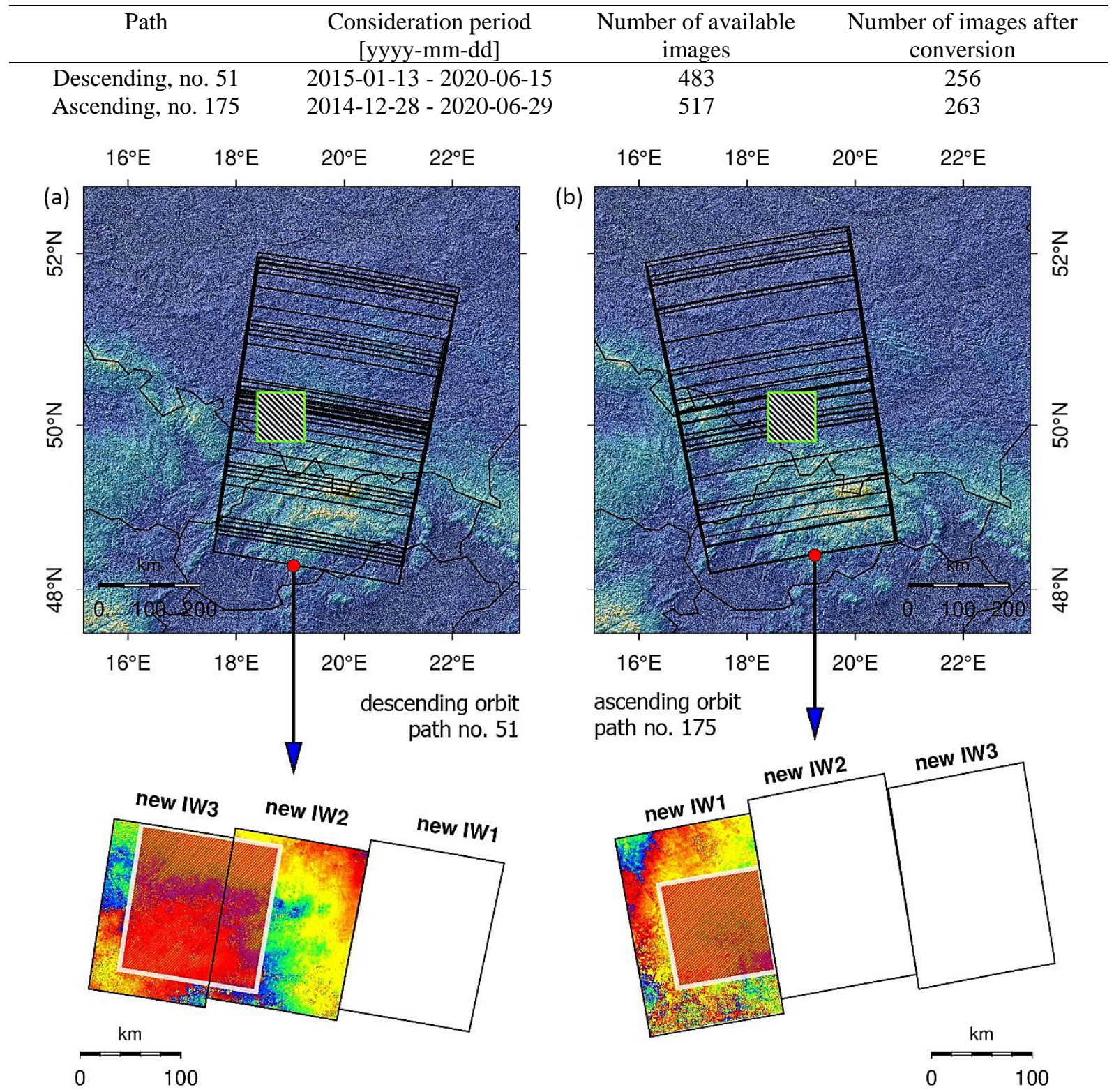

Fig. 2 Spatial coverage of available radar data for: (a) orbits 51 and (b) 175. The range of analyzed radar data after initial processing is shown below (please see Section Processing).

with Snaphu (Chen et al., 2002). Wave phase correction in relation to the ground surface was performed with the data from Shuttle Radar Topography Mission (SRTM) version 1 (Farr et al., 2007). A preliminary analysis of the spatial range of SAR images for the selected paths demonstrated that the investigated area is fully covered by a relatively limited number of frames. Frames define the spatial range of each SAR image, which for a specific orbit and area may be changeable for particular acquisition (these changes occur in the azimuthal plane). Therefore, in the majority of cases, the area is cut by the borders between the successive frames in a particular path (Fig. 2). Additionally, in the case of the descending path, the analyzed area is located at the intersection of two swaths. For the above reasons, raw data required modification prior to calculating the time series. This processing consisted in combining two or even three frames from a particular acquisition and subsequently in cutting the new data to the previously defined borders. In the next step, each sub-swath from the previously selected set of images was joined sequentially and simultaneously the new image was cut to the required range. Table 1 contains the data related to the preliminary data processing. Appendix 1 includes a visualization of the interferogram networks for the ascending and descending paths.

\section{MANIFESTATIONS OF THE INFLUENCE ON THE SURFACE}

Figure 3 shows the cumulative line-of-sight (LOS) displacement values for the period from the 

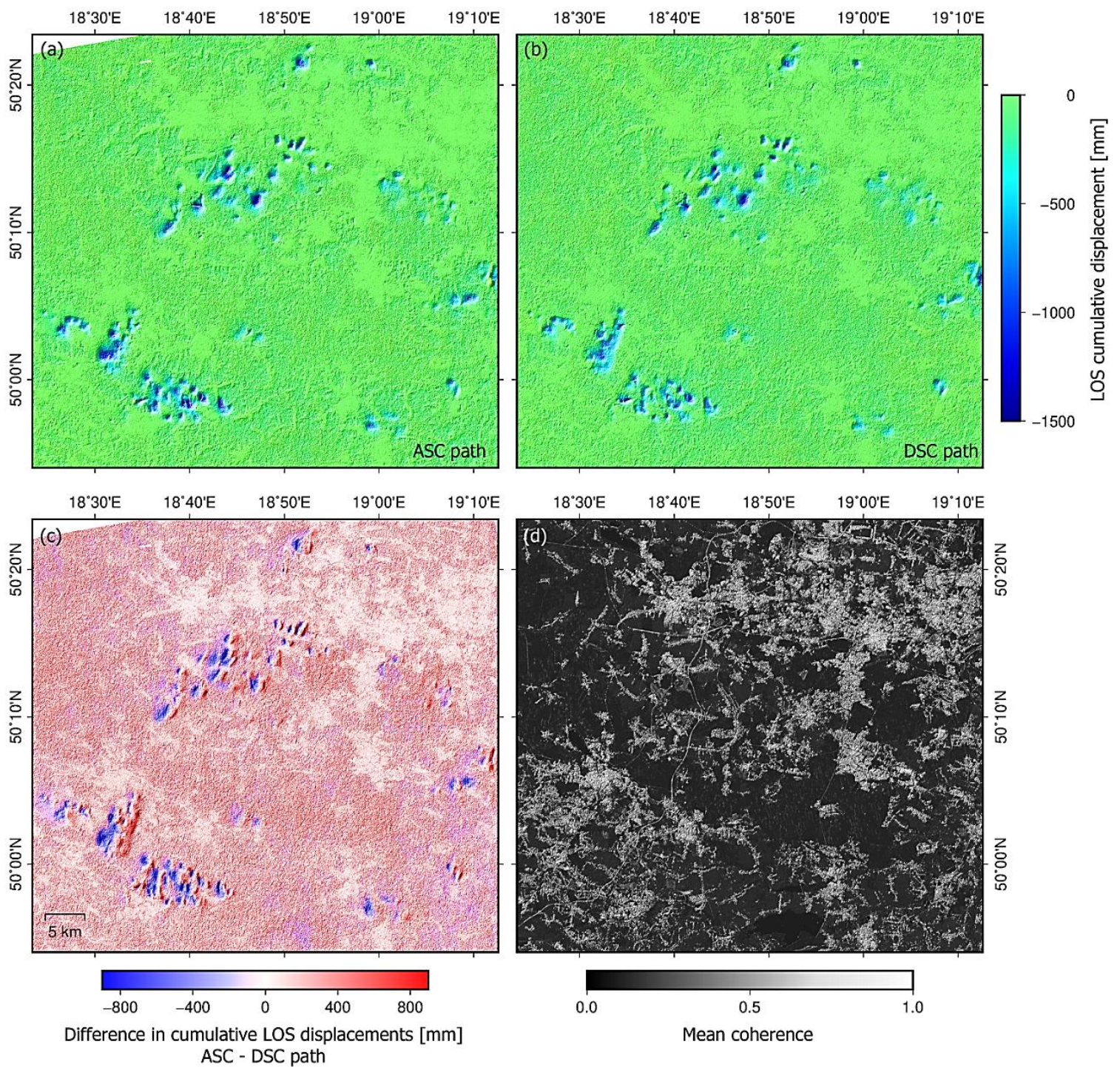

Fig. 3 Cumulative LOS displacement values for: (a) ascending path, (b) descending path; (c) differences between the LOS displacements from the ascending and descending paths; (d) mean coherence values of the interferograms from the descending path.

beginning of 2015 to the end of the second quarter 2020 for the ascending path (Fig. 3 (a)) and for the descending path (Fig. 3 (b)). The image below is a raster of differences between the LOS displacements from the ascending and descending paths (Fig. 3 (c)) and mean coherence values of the interferograms from the descending path (Fig. 3 (d)). Both rasters (ascending and descending LOS) illustrate numerous subsidence troughs, which are the result of underground mining activity in the USCB. The subsidence areas are concentrated mainly in the region of the Upper Silesian urban area and of the Rybnik Coal Region. The displacement images from both paths clearly show areas which have high coherence and overlap with the urban areas.

The LOS displacement values in the areas of the subsidence troughs are comparable for the data from both paths, and their values reach $-1500 \mathrm{~mm}$. The spatial distribution of the recorded LOS subsidence between the ascending and descending path is seemingly coherent (no relative differences are observed). However, direct comparison between two maps (from the ascending path and from the descending path) of the cumulative LOS displacements (subtraction) demonstrates significant differences, particularly in the E-W plane (Fig. 3 (c)). The troughs identified on the basis of the descending path are displaced by approx. 200-300 m towards East relative to the troughs identified from the ascending path. This phenomenon is obvious and strictly related to both the geometry of the SAR system and the character of displacements due to mining activity. Within the subsidence trough, vertical displacements are accompanied by horizontal displacements, which are included in the LOS vector in the E-W plane.

Figure 4 shows an analysis of LOS displacements for the descending path, for an area located in the western part of the USCB. The top part 

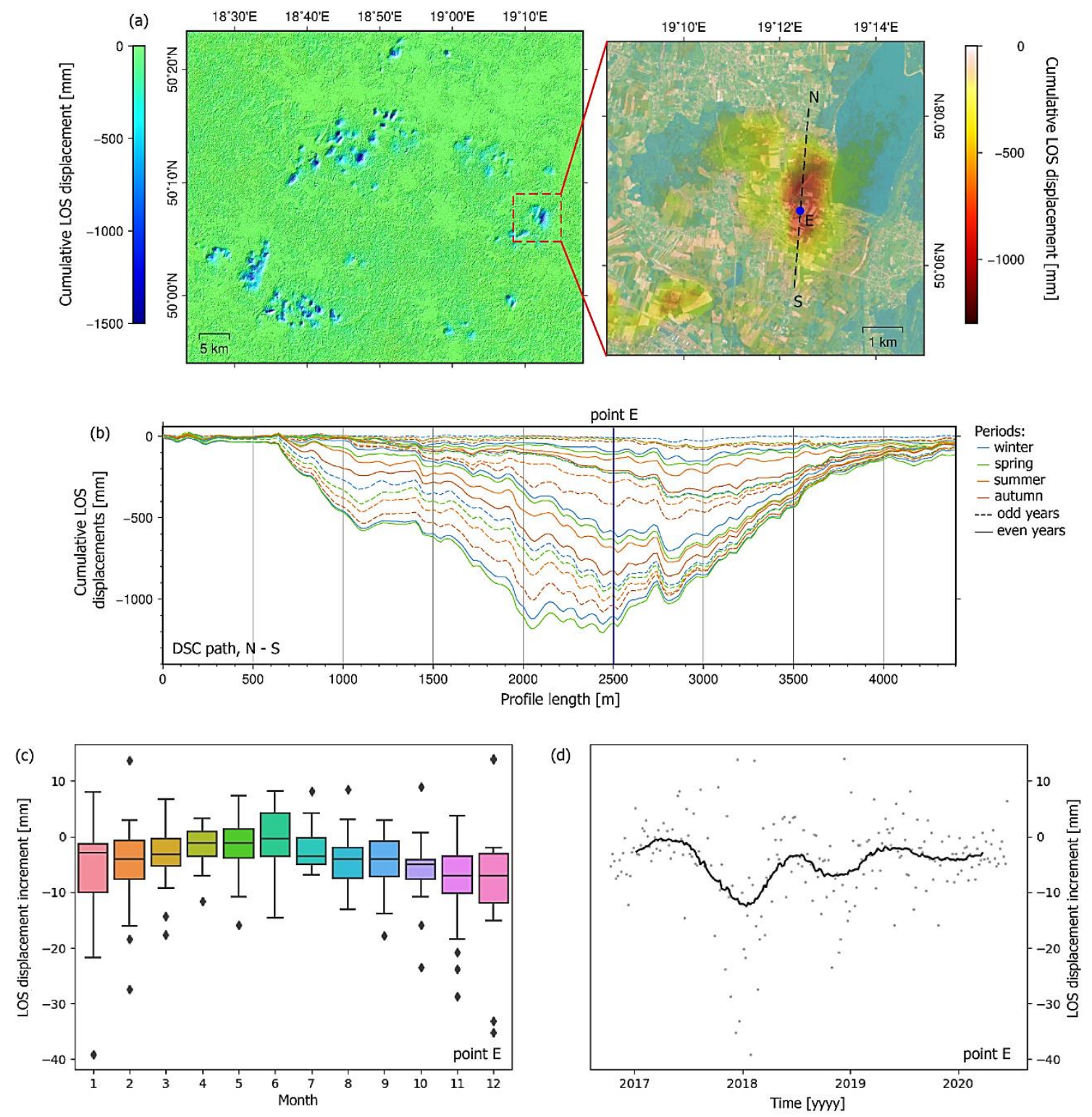

Fig. 4 Analysis of LOS displacements for an area located in the western part of the USCB: (a) the location of the trough; (b) N-S profile for the time series of the cumulative (quarterly) LOS displacements; (c) box plots for increments of LOS displacements; (d) monthly moving average trend.

of the image (Fig. 4 (a)) shows the location of the trough, the profile and the location of measurement point E. Inside (Fig. 4 (b)), there is arranged a profile for the time series of the cumulative (quarterly) LOS displacements. The bottom part of the image shows an analysis of the time series for point E, represented in the form of box plots for increments of LOS displacements (between successive image acquisitions), divided into months (Fig. 4 (c)) and the trend, represented in the form of a monthly moving average (Fig. 4 (d)).

The investigated area is not intensively urbanized and its majority is agricultural land. The profile clearly shows the progress of the displacement in time (in space, from the South to the North). The increments on the right (South) are greater in the initial phase, while the increments on the left increase later. Point E was intentionally located in the central part of the profile, as the impact of the mining activity is visible there over the entire investigated period. Both the seasonal analysis (the box plot - Fig. 4 (c)) and the trend of the LOS displacement increments (Fig. 4 (d)) indicate that the displacement increments are higher in the winter period: from late fall (November) to early spring (March). The maximum values of subsidence increments were also observed only in this period. The winter period is also characterized by the greatest variability of the feature. The trend line also demonstrates a clear sinusoidal variability, with minimum values occurring regularly at the turn of the year. 


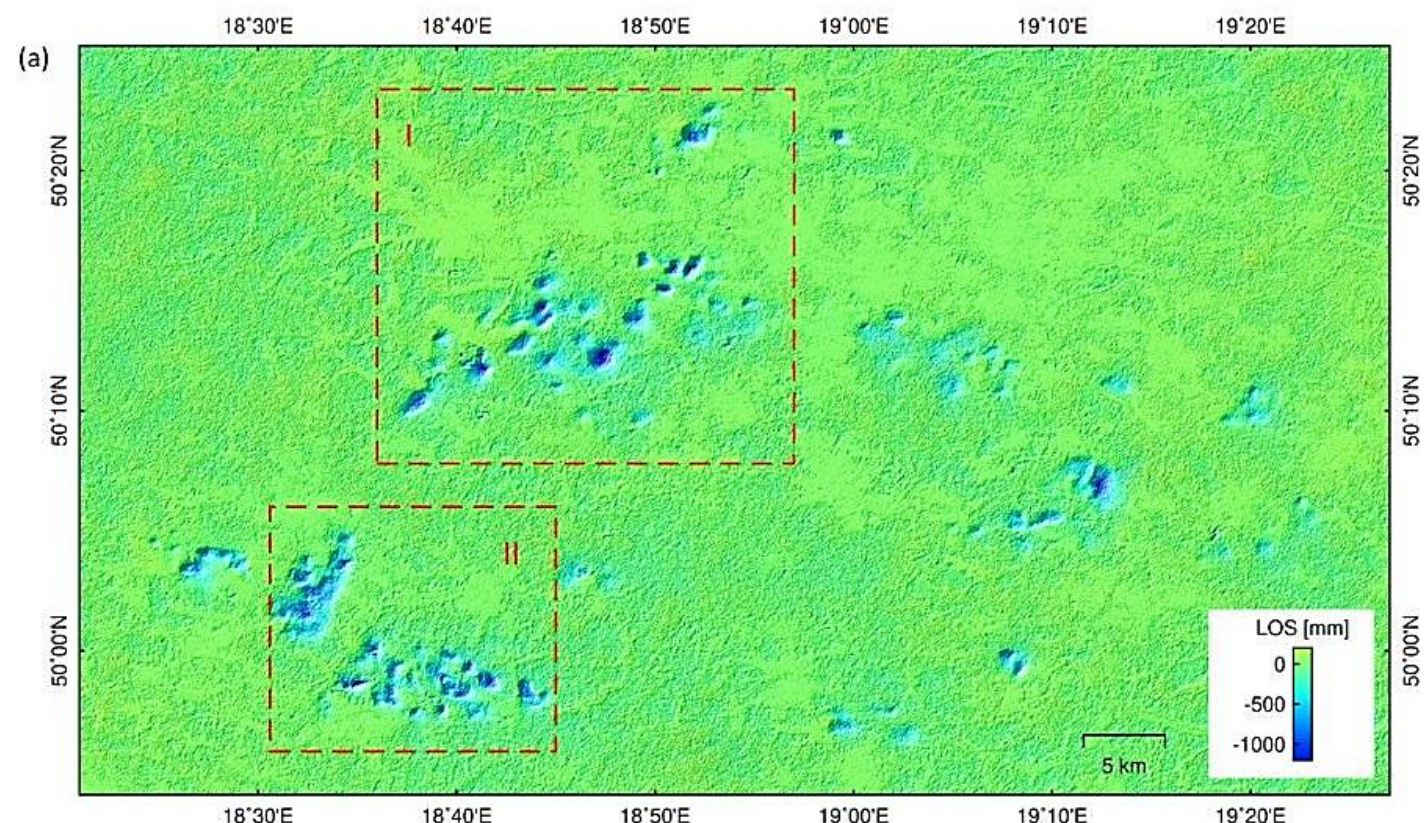

(b)
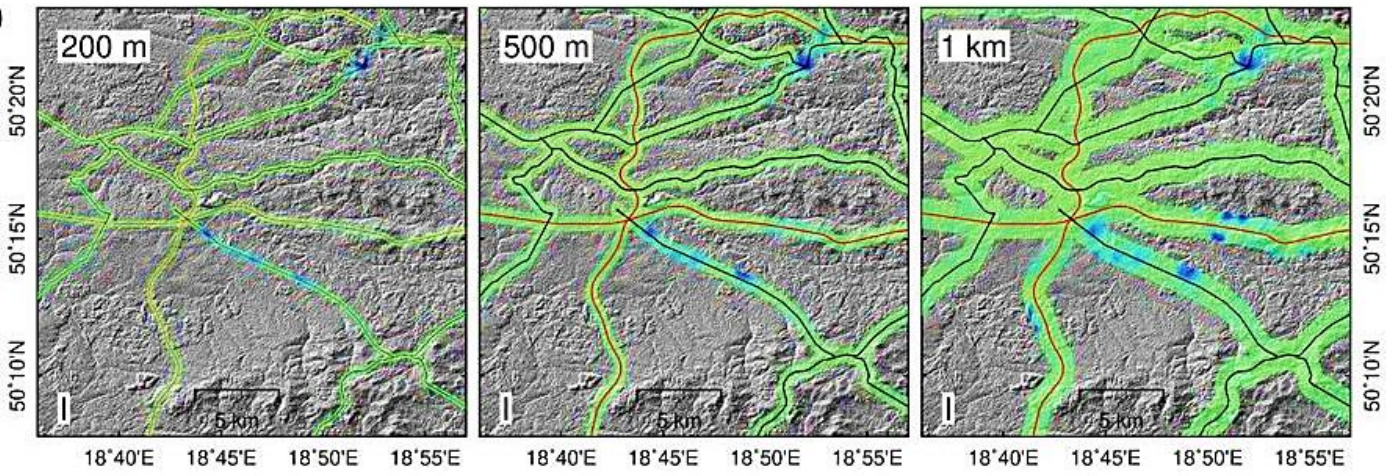

(c)
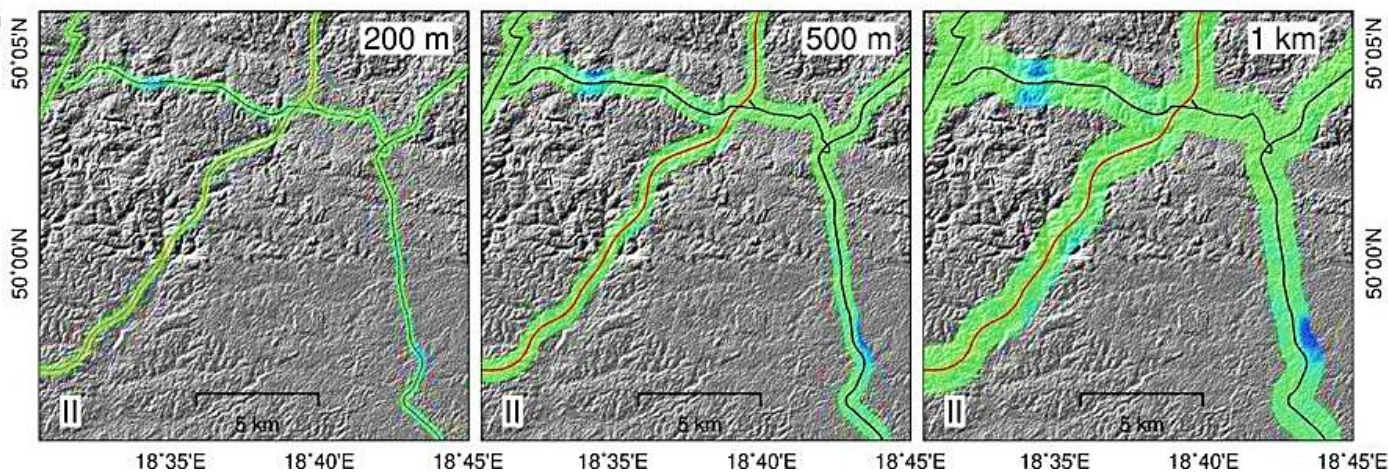

Fig. 5 (a) Location of the areas analyzed in terms of the crossing of subsidence troughs by road infrastructure. (b) Area I covering major part of the Upper Silesian urban area - analyzed buffer $200 \mathrm{~m}, 500 \mathrm{~m}$ and $1 \mathrm{~km}$ from the road axis (from left to right respectively) (c) Area II covering RCB area - analyzed buffer 200 $\mathrm{m}, 500 \mathrm{~m}$ and $1 \mathrm{~km}$ from the road axis (from left to right respectively). Red lines represent highways, while black lines represent national roads.

\section{IMPACT OF UNDERGROUND MINING IN THE REGIONS OF ROAD INFRASTRUCTURE}

Investigations of ground subsidence in the locations comprising important road infrastructure (highways, expressways and main roads) were performed for two areas (Fig. 5): N-W part of the USCB - from Gliwice to Sosnowiec (in the E-W plane) and from Bytom to Tychy (in the N-S plane) and also in the N-W part of the USCB which covers the Rybnik and the Jastrzębie Zdrój regions.

The first area (I) covers a major part of the Upper Silesian urban area, and therefore it has a dense road infrastructure. The area is also crossed by two highways (red lines): the A4 - the main communication route linking the West and the East in the South of Poland, and the A1 - linking the North 

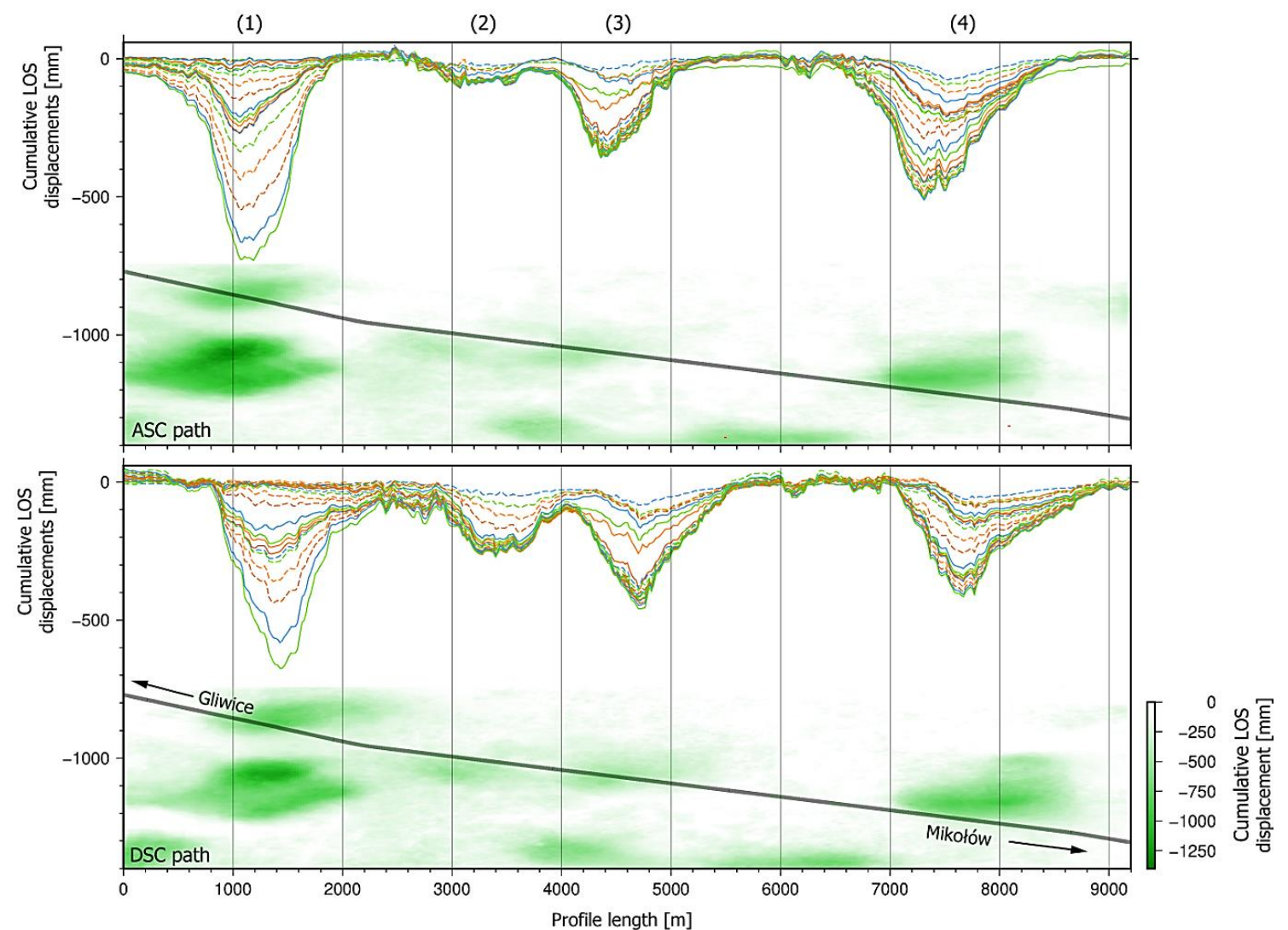

Fig. 6 Profiles of cumulative LOS displacements for the national road - for ascending (upper) and descending (bottom) paths. The color scheme for the profile lines is the same as in Figure 4 (b).

and the South of the country. Two subsidence troughs crossed by road infrastructure were observed in area (I) - they are related to mining activities performed within the region of Bytom (northern part of area I). One of the national roads was observed to go directly through an area of four subsidence troughs, which fact was described more extensively later in the article. Subsidence troughs are also located in the area of Highway A4, East of the highway intersection. However, the impact of mining activity is not observed at a distance of below $200 \mathrm{~m}$ from the road (Fig. 5, area I).

Area II (Fig. 5) covers the RCB area. The road network is as dense here as in the Upper Silesian urban area. In the N-S axis, the RCB area is crossed by Highway A1 (this section of the road was built between 2007 and 2014). No significant ground subsidence was observed in direct vicinity of the road infrastructure of Highway A1. As regards national roads, insignificant impact of mining activity in direct vicinity of the road was observed only in two areas (Fig. 5 (c)).

Figure 6 presents the profile of cumulative LOS displacements for the national road, which, as mentioned above, runs through 4 subsidence basins.

The maximum cumulative displacement values recorded in the area of the road strip reach $-700 \mathrm{~mm}$ (on the ascending path) and $650 \mathrm{~mm}$ (on the descending path). The profile shows that in the area of trough (1), the impact of mining activity became visible as late as in 2017. An additional increase in the subsidence velocity has been observed since the 3rd quarter of 2019. In the case of troughs (2) and (3), intensive mining impact was observed in 2015 . However, in 2016 the deformation velocity decreased, and in subsequent years ground surface subsidence has not been observed. A reverse relationship was observed for displacement increments between trough (1) and troughs (2) and (3). Trough (4) has variable subsidence velocities and they are observed throughout the analyzed period.

Figure 7 shows profiles through the above indicated subsidence trough, which is located in the area of Highway A1 (northern part of area A - see Fig. 5). The profile lines were drawn along the highway and the railway perpendicular to the highway. Figure 7 also contains time series of cumulative LOS displacements for points located in areas of the greatest subsidence (point A) and for the point located at the intersection of the LOS displacement $-200 \mathrm{~mm}$ contour line in the S-E direction from point A (point B). Importantly, the geographical locations of points $\mathrm{A}$ and $\mathrm{B}$ are different in the case of the ascending path (blue) and the descending path (red). ure

The intersection of the highway and the railway (for the results from both paths) is located in the area of the greatest ground surface subsidence. The 

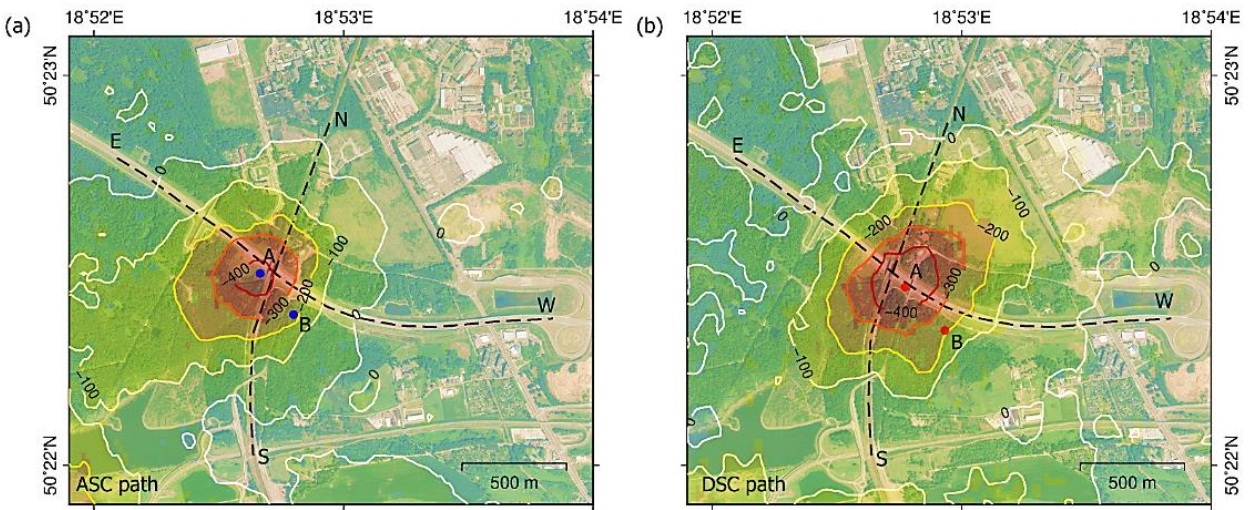

(c)

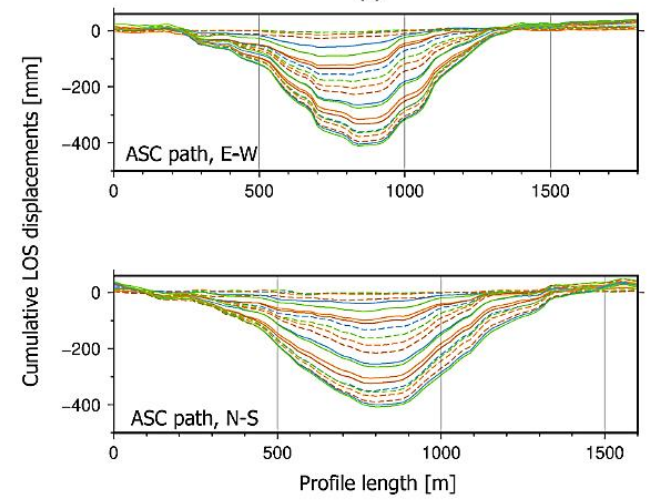

(d)
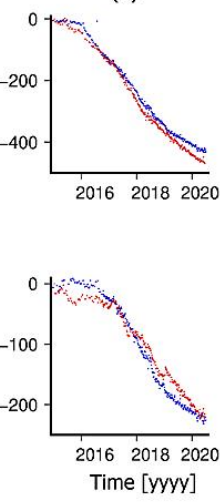

(e)
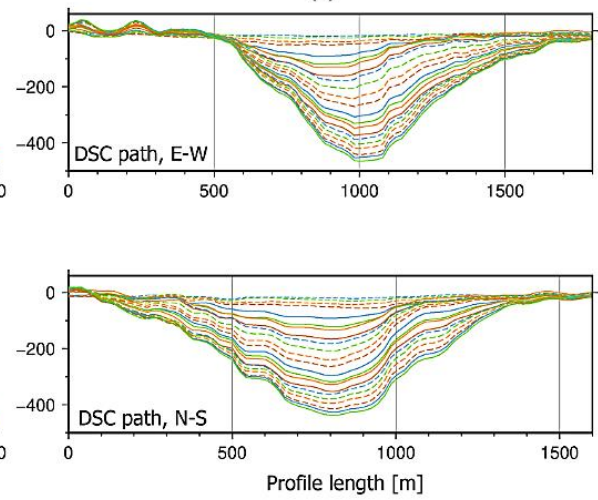

Fig. 7 Subsidence trough located in the area of Highway A1: cumulative LOS displacements, location of profiles and time series measurements points - respectively for ascending (a) and descending (b) paths; E-W and N-S profiles for the time series of the cumulative (quarterly) LOS displacements (blue - winter, green - spring, orange - summer, brown - autumn period) - respectively for ascending (c) and descending (e) paths; (d) time series of cumulative LOS displacements for points A and B, and from ascending (blue dots) and descending (red dots) paths.

quarterly displacement increments (Figs. 7 (c) and (e)) visible in the profiles have smooth and regular edges, indicating no time decorrelations for this object. The total cumulative LOS displacement values for the entire measurement period in this part of Highway A1 do not exceed $-450 \mathrm{~mm}$. In the case of both the E-W and N-S profiles, the second part of the profile shows lower subsidence increments in the initial period of the measurement (until 2017). This fact is also visible in the cumulative LOS displacement graphs for particular points. In the case of point $\mathrm{P}$, significant subsidence is observed only since 2017. A change (broadening) of the range of impact in the S-E direction is also visible, which may be related to the direction and progress of the mining face. Interestingly, the spatial differences in the locations of subsidence troughs for the ascending and the descending paths occur mainly in the E-W plane. This phenomenon may be observed by comparing the location of the bottom of the subsidence trough in the profiles. In the case of the $\mathrm{W}$-E profile this difference is approx. $200 \mathrm{~m}$. In the case of the N-S profile, the area is located in the same part of the profile for both paths.
In the area of the second trough, also located in the northern part of area (A) (Fig. 5), two national roads intersect, forming a large-scale road node. Profiles along the two roads are shown in Figure 8, which also represents time series for the cumulative LOS displacement values for point $\mathrm{C}$ located in the central part of the trough, where the maximum subsidence is observed, and for point D located in the area of the smaller trough, $\mathrm{S}-\mathrm{W}$ of the main subsidence trough.

In this case, the profiles are also regular, although the quarterly increments show some seasonal spatiotemporal variability, which is not related, however, with the vegetative period. The period of slower subsidence increments (from mid 2016 to mid 2019) in the area of the main trough, visible in the N$S$ profile and in the time series for points $C$ and $D$, is time-correlated with the period in which the impact of mining activity was observed in the area of the smaller trough (located S-W of the main trough). The abovedescribed relationship (the biggest displacement increment for point D in 2017 and 2018 and the smallest displacement increment for point $\mathrm{C}$ at the 

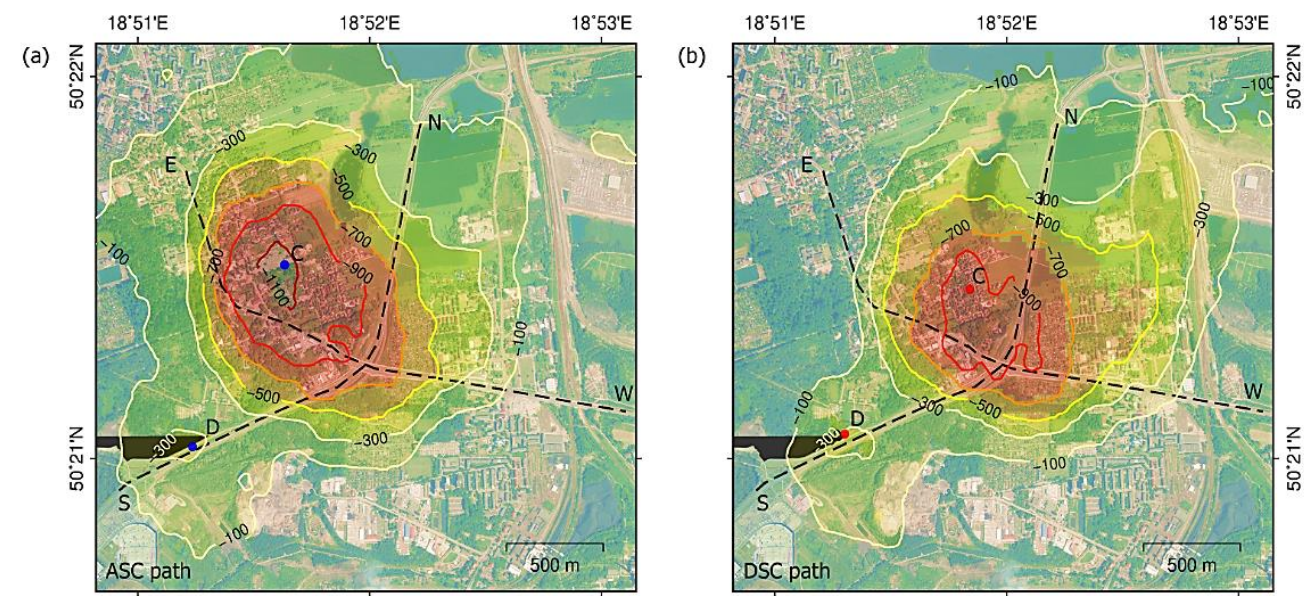

(c)

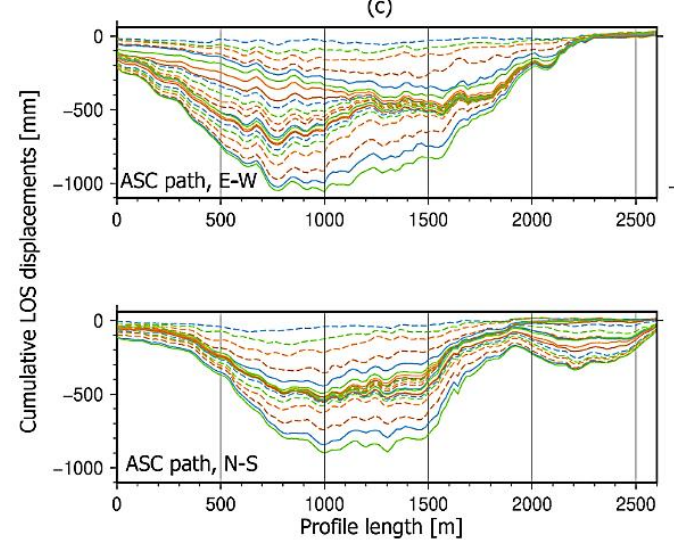

(d)
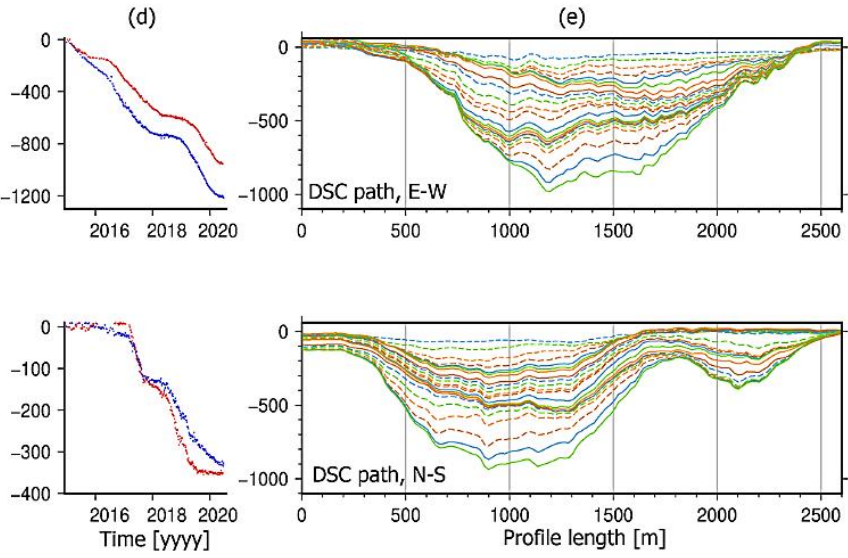

Fig. 8 Subsidence troughs located in the area of intersection of two national roads: cumulative LOS displacements, location of profiles and time series measurements points - respectively for ascending (a) and descending (b) paths; E-W and N-S profiles for the time series of the cumulative (quarterly) LOS displacements (blue - winter, green - spring, orange - summer, brown - autumn period) - respectively for ascending (c) and descending (e) paths; (d) time series of cumulative LOS displacements for points A and B, and from ascending (blue dots) and descending (red dots) paths.

same time) is also visible in Figure 9, which shows box plots for annual displacement increments for point $\mathrm{C}$ (located in the central part of the main trough) and for point $\mathrm{D}$ (located in the area of the smaller trough). It also allows a conclusion that the above-described variability is correlated with the operations of the mining plant (change of the mined wall or bed).

\section{DISPLACEMENTS IN THE AREA OF HEAPS}

Figure 10 shows area comprising three heaps (designated in blue) which are dump sites for mining waste. In the case of both the ascending and the descending paths, ground surface displacements were observed in this area. Numerous heaps in the USCB is not (yet) covered with vegetation, and therefore no decorrelations due to vegetation growth should occur. As indicated in the literature (Dobak et al., 2009), heap areas may be subject to ground subsidence of 1 to $2.5 \% \mathrm{H}$ (where $\mathrm{H}$ is the height of the heap). Such displacements are related to the phenomenon of consolidating the stored material. However, it is possible that the observed deformations are related to the mechanical movement of the material due to works performed on the active heap or to the secondary mining of the heap.

In the case of heap (2), the displacements occur practically only within the area of the heap, which indicates that the recorded subsidence is related to the above-presented factors. Importantly, a significant difference exists of the spatial distribution and the LOS displacement values between the ascending and the descending paths. Because of the geometry of both the SAR system and the measurement, this difference may suggest displacements having significant values of the horizontal (E-W) component. On the other hand, in the case of heaps (1) and (3), the displacements are also observed outside the borders of the heaps, possibly due to the impact of underground mining activity.

\section{SEISMIC EVENTS}

The results were also analyzed from the perspective of employing them in the SBAS technique to monitor the USCB for ground surface 


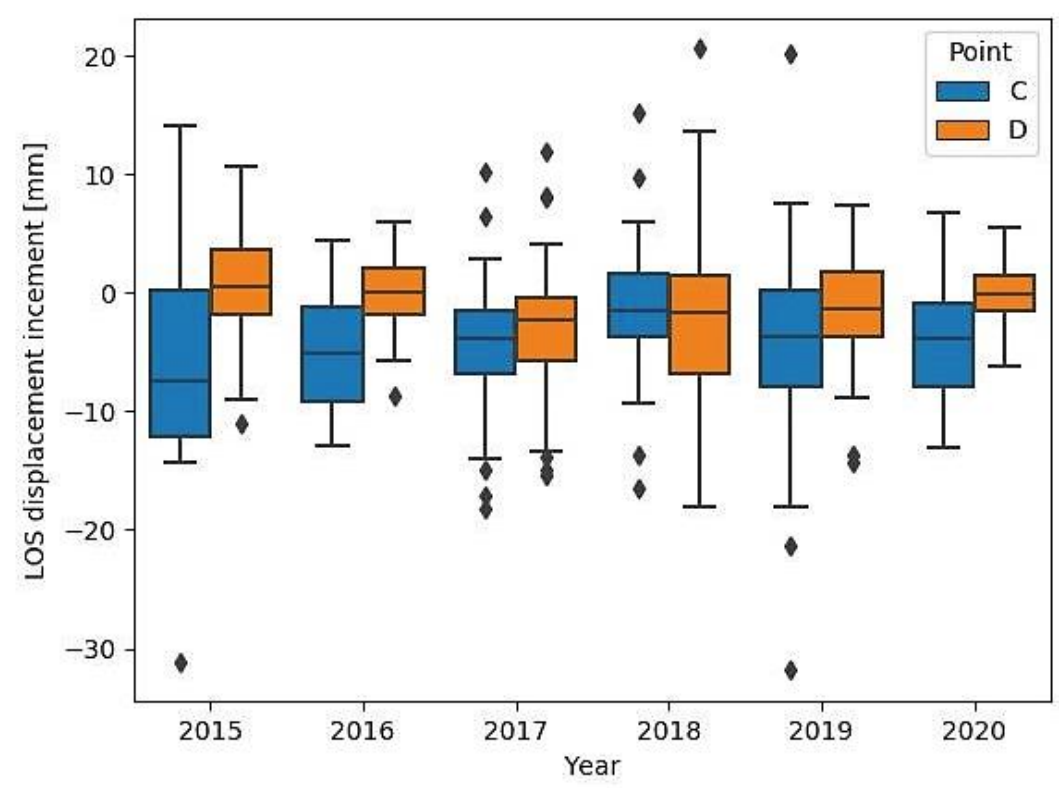

Fig. 9 Box plots for annual displacement increments for point $\mathrm{C}$ and for point $\mathrm{D}$ (see Fig. 8).
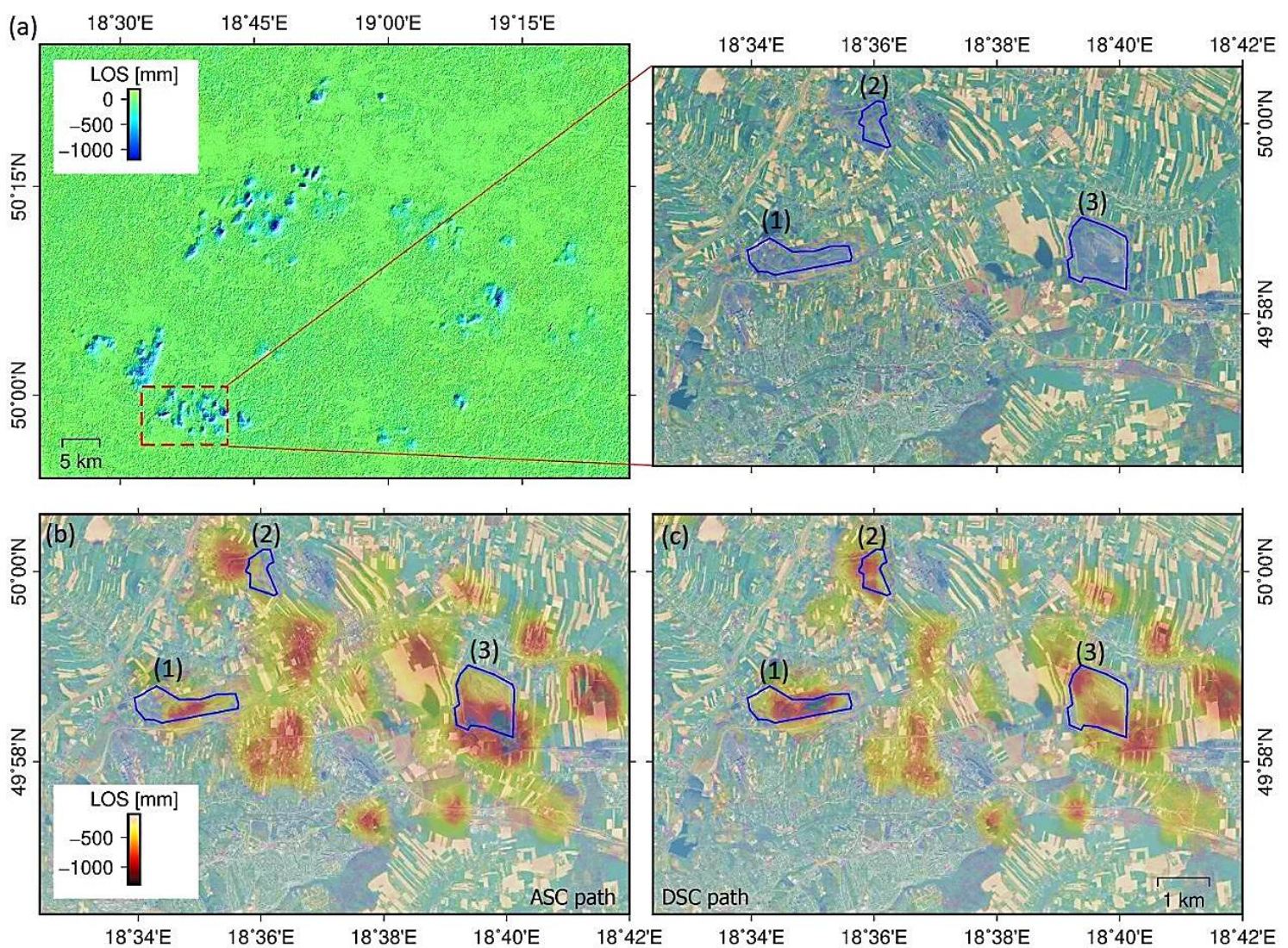

Fig. 10 Displacements in areas of dump sites for mining waste: (a) location of dump sites (blue lines), cuureulative LOS displacements - respectively for ascending (b) and descending (c) paths. 


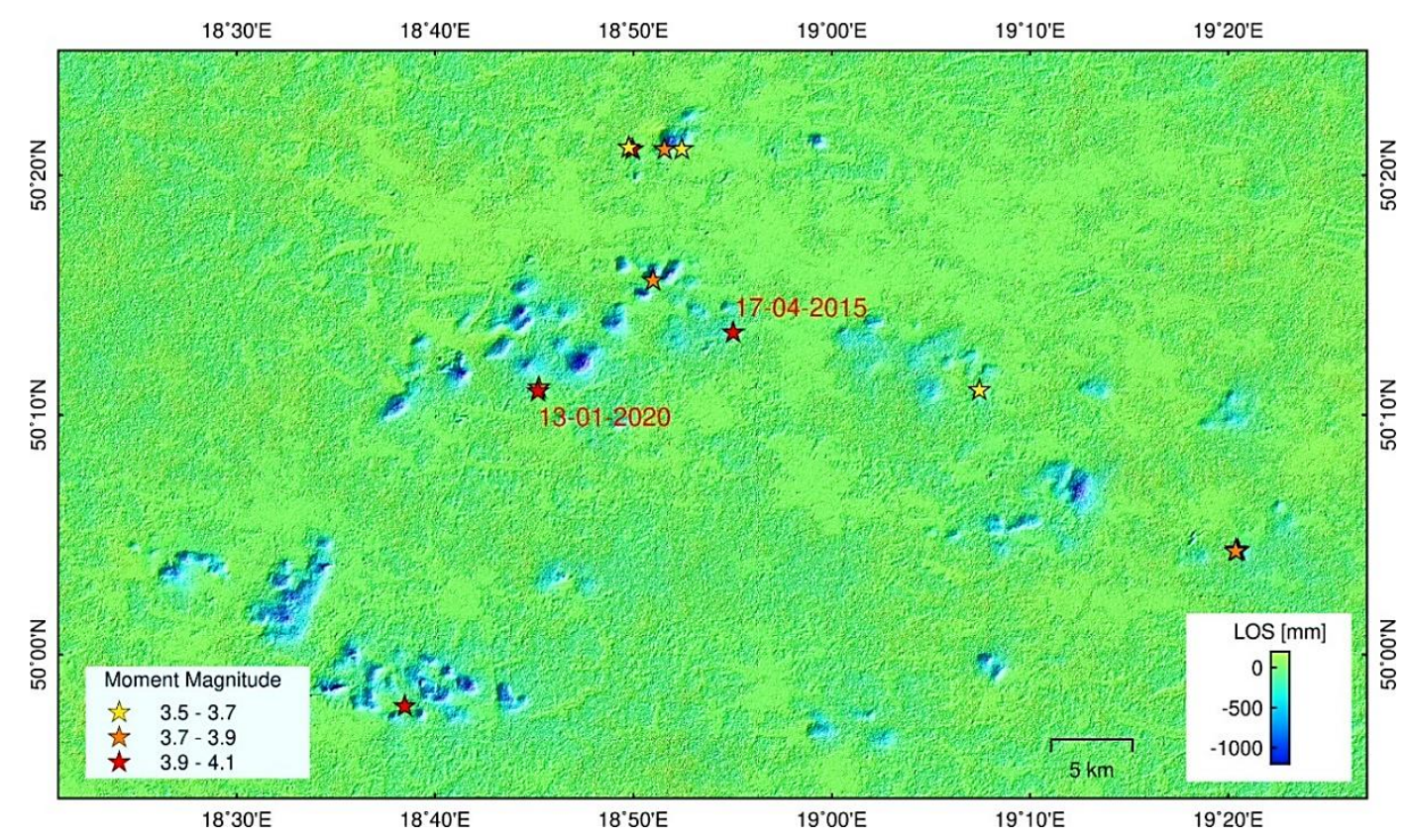

Fig. 11 Location of analyzed seismic events.

displacements due to tremors induced by mining activity. The analysis of the SBAS data in the regions of 13 powerful tremors (above $3.5 \mathrm{Mw}$ ) was performed. Their location is shown in Figure 11.

The results for two events are presented below: of Apr. 17, 2015 and Jan. 13, 2020. Figures 12 and 13 (respectively for tremors of Apr. 17, 2015 and Jan. 13, 2020) show cumulative displacement values and a profile for the ascending and the descending paths, for the closest date directly preceding (blue) and following (red) the event. Table 2, presents the numerical values of displacement increments before, immediately after and after the tremors (of Apr. 17, 2015 and Jan. 13, 2020).

For the tremor from Apr. 17, 2015, in the case of both paths, a significant displacement increment was observed (directly after the event) East of the region of the tremor. Importantly, this tremor occurred in the region of a subsidence trough, in which no significant displacement increment was recorded either before or after the tremor. Before the tremor, the average subsidence increments were about $4 \mathrm{~mm}$, after the tremor about $2 \mathrm{~mm}$, while immediately after the event the average subsidence increment was about $30 \mathrm{~mm}$ (based on data from both paths, see Table 2).

However, in the case of tremor from Jan. 13, 2020 , the increments of the subsidence values before the event averaged about $10 \mathrm{~mm}$ and after the event averaged about $13 \mathrm{~mm}$, while the average displacement immediately after the tremor averaged about $7 \mathrm{~mm}$ (based on data from both paths, see Table 2). In this instance, the increment of displacement immediately after the shock does not exceed the average values of increment of subsidence that occurred before and after the tremor. The analysis of other tremors also did not show significantly higher values of displacement increments immediately after the event.

\section{DISCUSSION}

This section will include a discussion of the advantages and disadvantages of the SBAS technique in the context of monitoring the influence of mining activity on the ground surface and in relation to the research results presented above. The SBAS technique, together with the method for combining data from several paths and frames proposed by the authors, allows observations of ground surface over a period of several years and in a regional scale. Importantly, in the USCB, in the region where hard coal is mined with the longwall system (especially with roof collapse), annual subsidence increments may reach up to $1 \mathrm{~m}$ (Kowalski, 2020). The obtained LOS displacement values do not exceed, however, $-1500 \mathrm{~mm}$ over 5.5 years (an average of $27 \mathrm{~cm}$ per year). This number indicates significant underestimation of the measurement results. Therefore, the results of the SBAS-based displacement measurements can be interpreted only qualitatively. Apart from the obvious influence of the limitations of the SBAS technique, such low average values of annual subsidence are also caused by the fact that the influence of mining activity does not manifest itself on the surface in a time-constant manner. In addition, increasing the frequency of SAR image acquisition (from 12 to 6 days - owing to the introduction of the Sentinel 1B satellite to the orbit, since October 2016) increased the values of maximum annual displacement increments (Table 3).

Changes in the spatial distribution of displacement increment values over time (e.g., such as those shown in Figure 4 (b)), may be related to changes in the location of the mining longwall and the progress of the mining front. Interestingly, the changes have been observed to have a seasonal character (Fig. 4 (c)). Seasonality may be related to changes in mining operations intensity. However, observed 

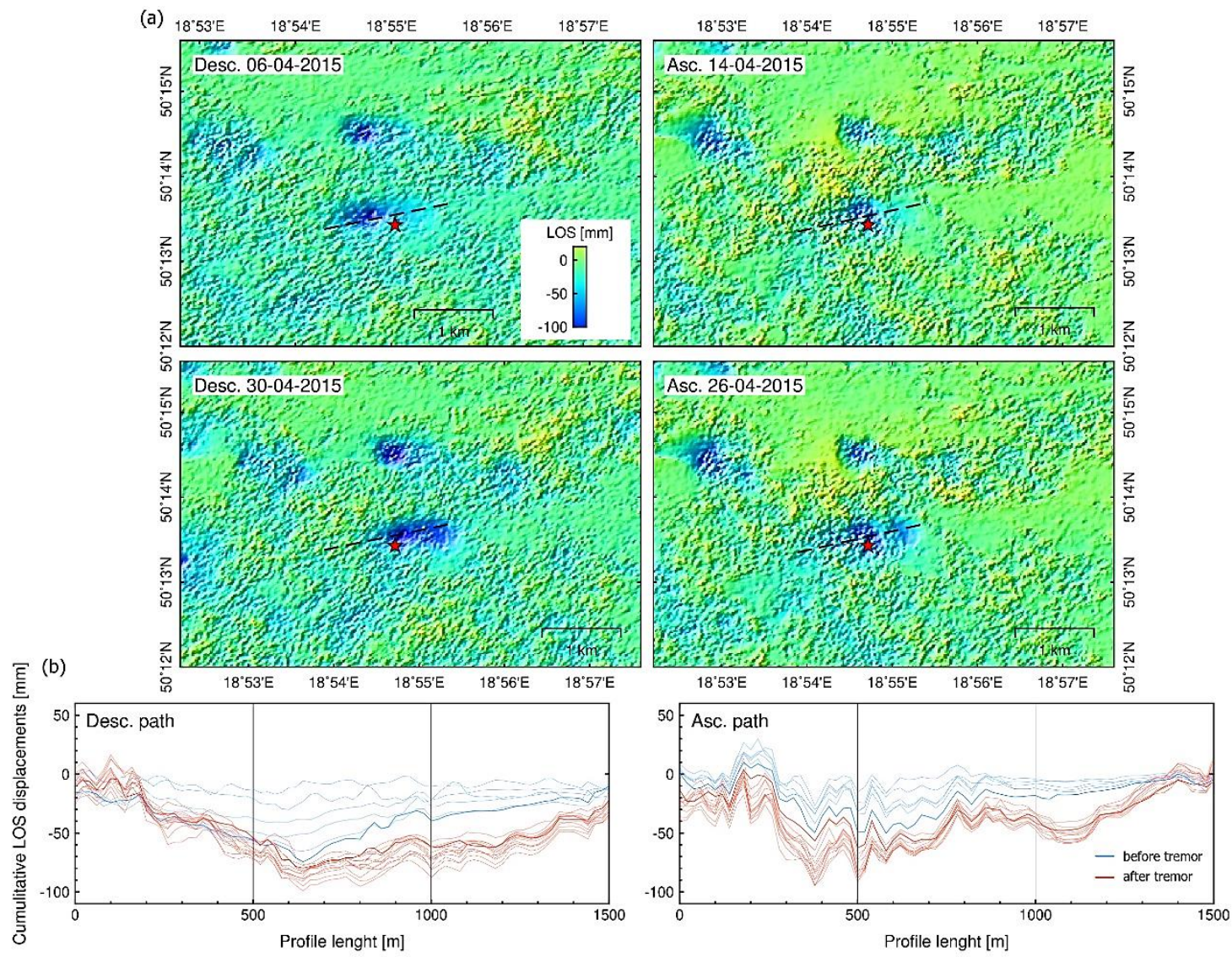

Fig. 12 (a) Cumulative displacements for the descending path before the Apr. 17, 2015 tremor (top left) and after him (bottom left) and for the ascending path before the Apr. 17, 2015 tremor (top right) and after him (bottom right) (b) Profiles by subsidence trough preceding (blue) and following (red) the Apr. 17, 2015 tremor for descending (left) and ascending (right) paths.

Table. 2 Increments of ground displacement, before, immediately after and after the Apr. 17, 2015 and Jan. 13, 2020 tremors.

\begin{tabular}{|c|c|c|c|c|c|c|c|c|}
\hline & \multicolumn{4}{|c|}{ 2015-04-17 tremor } & \multicolumn{4}{|c|}{ 2020-01-13 tremor } \\
\hline & \multicolumn{2}{|c|}{ Descending path } & \multicolumn{2}{|c|}{ Ascending path } & \multicolumn{2}{|c|}{ Descending path } & \multicolumn{2}{|c|}{ Ascending path } \\
\hline & Date* & $\begin{array}{c}\text { LOS disp. } \\
\text { increment } \\
{[\mathrm{mm}]}\end{array}$ & Date* & $\begin{array}{c}\text { LOS disp. } \\
\text { increment } \\
{[\mathrm{mm}]}\end{array}$ & Date* & $\begin{array}{c}\text { LOS disp. } \\
\text { increment } \\
{[\mathrm{mm}]}\end{array}$ & Date* & $\begin{array}{c}\text { LOS disp. } \\
\text { increment } \\
{[\mathrm{mm}]}\end{array}$ \\
\hline \multirow{6}{*}{$\begin{array}{l}\overrightarrow{0} \\
\tilde{0} \\
0 \\
0 \\
0 \\
0 \\
0 \\
0\end{array}$} & 2015-01-24 & reference & 2014-12-27 & reference & $2020-12-10$ & reference & $2020-12-12$ & Reference \\
\hline & 2015-02-05 & -13.3 & $2015-02-13$ & +0.6 & $2020-12-16$ & -2.1 & $2020-12-18$ & -8.4 \\
\hline & 2015-03-01 & +5.3 & 2015-03-09 & -7.4 & $2020-12-22$ & -11.6 & $2020-12-24$ & -12.4 \\
\hline & 2015-03-13 & -8.6 & 2015-03-21 & +2.0 & $2020-12-28$ & -8.5 & 2021-01-01 & -8.2 \\
\hline & $2015-03-25$ & -9.8 & 2015-04-02 & -3.6 & 2021-01-04 & -5.8 & 2021-01-06 & -8.1 \\
\hline & 2015-04-06 & +0.4 & 2015-04-14 & -2.8 & 2021-01-10 & -16.4 & 2021-01-12 & -15.4 \\
\hline \multirow{6}{*}{ 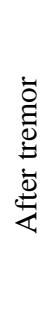 } & 2015-04-30 & -31.1 & 2015-04-26 & -29.6 & 2021-01-16 & -7.5 & 2021-01-18 & -6.0 \\
\hline & 2015-05-12 & +8.3 & 2015-05-08 & +7.1 & 2021-01-22 & -8.4 & 2021-01-24 & -10.7 \\
\hline & $2015-05-24$ & -10.5 & $2015-05-20$ & -8.9 & 2021-01-28 & -10.9 & 2021-01-30 & -8.2 \\
\hline & 2015-06-05 & +2.5 & 2015-06-01 & -2.4 & 2021-02-03 & -19.6 & 2021-02-05 & -14.2 \\
\hline & 2015-06-17 & +0.3 & $2015-06-25$ & -4.4 & 2021-02-09 & -6.5 & 2021-02-11 & -12.6 \\
\hline & 2015-06-29 & -7.4 & 2015-07-19 & -2.7 & 2021-02-15 & -0.9 & 2021-02-17 & -18.3 \\
\hline
\end{tabular}

*Dates are given in yyyy-mm-dd 

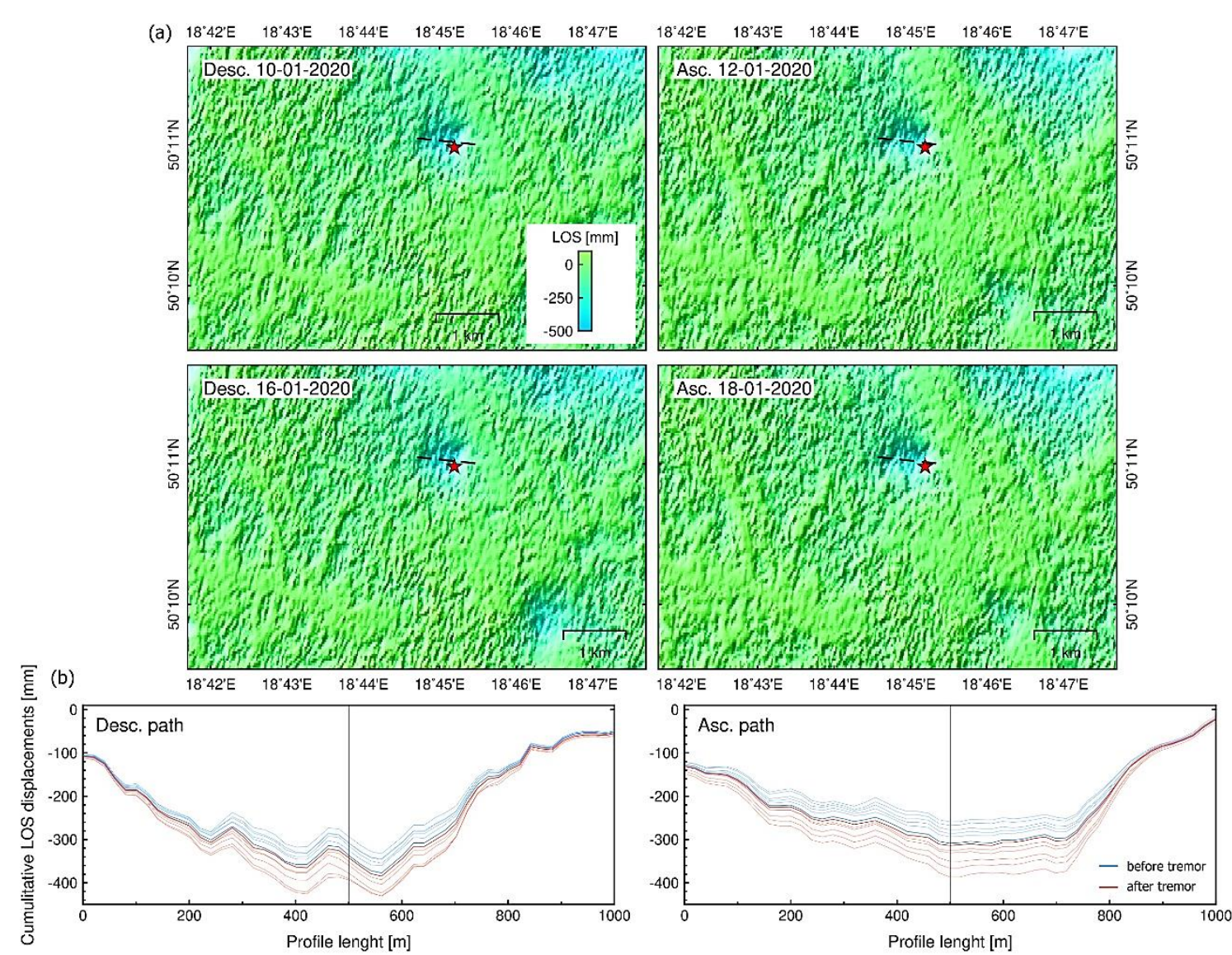

Fig. 13 (a) Cumulative displacements for the descending path before the Jan. 13, 2020 tremor (top left) and after him (bottom left) and for the ascending path before the Jan. 13, 2020 tremor (top right) and after him (bottom right) (b) Profiles by subsidence trough preceding (blue) and following (red) the Jan. 13, 2020 tremor for descending (left) and ascending (right) paths.

Table 3 Maximum annual increments of LOS displacements.

\begin{tabular}{cccccc}
\hline Year & 2015 & 2016 & 2017 & 2018 & 2019 \\
\hline max LOS disp.[mm per year] & -244 & -251 & -387 & -359 & -307 \\
\hline
\end{tabular}

seasonality is correlated with summer and winter periods (vegetation and non-vegetation seasons), it is considered more probable that lower summer increments are related to vegetation-induced signal decorrelations.

Also, the distribution of the LOS displacements (between the results from the ascending and the descending paths) is shifted, mainly in the E-W plane. This issue may be solved by decomposing the LOS vector into its vertical and horizontal components (in the E-W plane). The spatial distribution of vertical displacements thus obtained will be the resultant of the data from both paths. In the case of the N-S plane, the results are spatially coherent (Fig. 3 (c)), which is related to the imaging geometry of the SAR system (for Sentinel-1). Also the LOS displacement values and their variability, based on the data from the two paths, are comparable. This fact indicates a high relative measuring accuracy. Despite a significant underestimation of the results, the SBAS measurements are a valuable source of data. Time series of displacement increments allow observations and analyses of the manifestations on the ground surface of the influence of underground mining activities, which in combination with detailed mining data may be a valuable source of information, e.g. with respect to investigations of the time coefficient. It is also possible to monitor spatial trends of ground surface displacements, which is particularly important in the case of mining systems characterized by fast progress of the mining face. The highest displacement values were observed in the area of mining heaps, which may be attributed to the consolidation of the stored material. This is a slower process than ground subsidence due to mining activity (at least in the USCB), and therefore InSAR-based measurements provide seemingly higher subsidence values. The displacements in the area of the heaps are most probably not related to the underground mining activity (the heaps are intentionally not located in 
Table 4 Opportunities to use SBAS measurement results for monitoring of specific issues in the USCB area.

\begin{tabular}{lcccc}
\hline $\begin{array}{l}\text { The true value of the land } \\
\text { displacement (LOS) }\end{array}$ & $\begin{array}{c}\text { Trends, variability } \\
\text { over time }\end{array}$ & Location & $\begin{array}{c}\text { Detection of new } \\
\text { influences }\end{array}$ & $\begin{array}{c}\text { Detection of displacements } \\
\text { connected with tremors }\end{array}$ \\
\hline $\begin{array}{l}\text { Verification required } \\
\text { (using independent } \\
\text { measurement techniques) }\end{array}$ & Yes & Yes $^{1}$ & Yes & Yes/No $^{1}$ \\
\hline
\end{tabular}

areas of intensive mining activity, as significant ground subsidence would compromise the stability of the heap). Additionally, the heaps with identified significant ground subsidence are not covered by vegetation - hence no time decorrelations are observed. Therefore, the identified displacement values are reliable and can be attributed to the phenomenon of material consolidation.

The authors also demonstrated that in the USCB region, in which mining is performed with the use of longwall systems and the displacement increments are high and not time-constant, it is difficult to determine conclusively whether the observed displacements are a direct result of direct mining influences or were caused by a tremor, only based on InSAR-SBAS data. Other publications (Pawłuszek-Filipiak and Borkowski, 2021) also indicate that InSAR techniques (DInSAR, PSI, SBAS) used in the USCB region do not allow a definite conclusion whether the observed displacement is due to direct impact or secondary influence (tremor). However, as pointed in Milczarek (2019), in the areas in which mining is performed with the use of other systems (e.g. the Legnica-Głogów Copper Belt and the room-and-pillar system) and in which displacement increments are regular and smaller, the SBAS technique allows an effective monitoring of the influence of induced seismic tremors on the ground surface. However, it should be mentioned that seismic events induced by mining activities may affect the surface of the ground in different ways, leading (or not) to displacement. It dependent on a few factors, including: the magnitude and depth of the tremor, geological and tectonic conditions, type of applied mining excavation system, and the nature of the tremor source - double-couple or not double-couple (volume change, or uniaxial compression or extension) forces (Dubiński et al., 2005; Sen et al., 2013; Rudziński et al., 2019 and Milczarek et al., 2021). Therefore, the phenomena of the influence of induced seismic tremors on the ground surface is a complex issue that requires interdisciplinary analysis, where SBAS-InSAR data are also applicable.

Table 4 presents information on a particular phenomenon related to the impact of underground mining activity on the ground surface (in the USCB region), as obtainable from the SBAS-based time series analysis. Although some of this information is of a qualitative character only, high temporal resolution and spatial range give it a certain value.

\section{CONCLUSION}

This article presents a method of combining two paths and numerous SAR images for the data obtained from SAR satellites: Sentinel $1 \mathrm{~A} / \mathrm{B}$. The method allows the monitoring of ground surface displacements in a regional scale. The measurements were performed with the use of the SBAS technique, for the USCB region, in which hard coal is mined with the longwall system. The SBAS-based measurements, unverified using independent geodetic methods, for the USCB region should be interpreted as qualitative rather than quantitative information - while the displacements can be monitored for whether they appear or disappear, or for their spatial and temporal trends, their values may be underestimated. The employed measurement technique also allows the monitoring of the impact of mining activity on the elements of road infrastructure. Except for a limited number of cases (e.g. Bytom), no major ground displacements were observed in the areas of the main roads (national and regional roads), which is the result of implementing protective pillars in these areas. Another analyzed aspect was the possibility of using the SBAS technique to monitor secondary displacements (due to tremors). The technique was demonstrated to have a limited effectiveness in this case - it is impossible to distinguish between a displacement being directly caused by mining activity and a displacement due to a tremor. The areas covered with vegetation in the spring and in the summer were also demonstrated to have lower subsidence increment values, this fact being caused by the decorrelations due to vegetation.

The authors indicate, however, that although SBAS-based monitoring of ground displacements due to underground mining activity can be used only qualitatively in the USCB areas, it can still provide substantial information. In addition, a combination of the obtained results with the data on the mining operations would allow a more complex investigation of such parameters as the time coefficient of the manifestation of mining influence, which until present was possible only on the basis of data interpolated from levelling surveys on measuring lines.

\footnotetext{
${ }^{1}$ Taking into account the shift related to the geometry of the LOS vector.

${ }^{2}$ Dependent on several factors mentioned in the Discussion.
} 


\section{REFERENCES}

Baek, J., Kim, S.-W., Park, H.-J. et al.: 2008, Analysis of ground subsidence in coal mining area using SAR interferometry. Geosci. J., 12, 277-284. DOI: $10.1007 / \mathrm{s} 12303-008-0028-3$

Berardino, P., Fornaro, G., Lanari, R. and Sansosti, E.: 2002, A new algorithm for surface deformation monitoring based on small baseline differential SAR interferograms. IEEE Trans. Geosci. Remote Sens., 40, 2375-2383. DOI: 10.1109/TGRS.2002.803792

Blachowski, J., Kopeć, A., Milczarek, W. and Owczarz, K.: 2019, Evolution of secondary deformations captured by satellite radar interferometry: Case study of an abandoned coal basin in SW Poland. Sustainability, 11, 884. DOI: $10.3390 / \mathrm{su} 11030884$

Burtan, Z.: 2016, The importance of associated natural hazards in the Upper Silesian Coal Basin. Mining Review, 72, 11, (in Polish).

Carnec, C. and Delacourt, C.: 2000, Three years of mining subsidence monitored by SAR interferometry, near Gardanne, France. J. Appl. Geophys., 43, 43-54. DOI: 10.1016/S0926-9851(99)00032-4

Carnec, C., Massonnet, D. and King, C.: 1996, Two examples of the use of SAR interferometry on displacement fields of small spatial extent. Geophys. Res. Lett., 23, 3579-3582. DOI: 10.1029/96GL03042

Chen, C.W. and Zebker, H. A.: 2002, Phase unwrapping for large SAR interferograms: statistical segmentation and generalized network models. IEEE Trans. Geosci. Remote Sens., 40, 1709-1719. DOI: $10.1109 /$ TGRS.2002.802453

Colesanti, C., Mouelic, S.L., Bennani, M. et al.: 2005, Detection of mining related ground instabilities using the Permanent Scatterers technique - a case study in the east of France. Int. J. Remote Sens., 26, 201-207. DOI: $10.1080 / 0143116042000274069$

Dobak, P., Woźniak, H. and Nieć, M. (eds.): 2009, Principles of documenting geological and engineering conditions for the purposes of mine liquidation. Ministry of Environment, Warszawa, (in Polish).

Doin, M.-P., Lodge, F., Guillaso, S. et al.: 2011, Presentation of the small baseline NSBAS processing chain on a case example: The Etna deformation monitoring from 2003 to 2010 using Envisat data. In: FRINGE 2011 ESA Conference.

Dubiński, J., Stec, K. and Lurka, A.: 2005, Impact of seismic tremors on the surface depending on their physical parameters, 1st ed. Central Mining Institute, Katowice, (in Polish).

Farr, T., Rosen, P.A., Caro, E., Crippen, R., Duren, R., Hensley, S., Kobrick, M., Paller, M., Rodriguez, E., Roth, L., Seal, D., Shaffer, S., Shimada, J., Umland, J., Werner, M., Oskin, M., Burbank, D. and Alsdorf, D.: 2007, The shuttle radar topography mission. Rev. Geophys., 45, 1-33. DOI: 10.1029/2005RG000183

Ferretti, A., Prati, C. and Rocca, F.: 2000, Nonlinear subsidence rate estimation using permanent scatterers in differential SAR interferometry. IEEE Trans. Geosci. Remote Sens., 38, 2202-2212. DOI: $10.1109 / 36.868878$

Ferretti, A., Prati, C. and Rocca, F.: 2001, Permanent scatterers in SAR interferometry. IEEE Trans. Geosci. Remote Sens., 39, 8-20. DOI: 10.1109/36.898661

Graniczny, M., Colombo, D., Kowalski, Z., Przyłucka, M. and Zdanowski, A.: 2015, New results on ground deformation in the Upper Silesian Coal Basin (southern Poland) obtained during the DORIS Project (EU-FP 7). Pure Appl. Geophys., 172, 3029-3042. DOI: $10.1007 / \mathrm{s} 00024-014-0908-6$

Hanssen, R.F.: 2001, Radar interferometry: Data interpretation and error analysis. Remote Sensing and Digital Image Processing. Springer Netherlands.

Jureczka, J. and Nowak, G.J.: 2016, A short overview of data on geological investigation of the Polish bituminous coal basins. Geological Review, 64, (in Polish).

Kaszowska, O.: 2007, Impact of underground mining on surface of terrain. Ecological Issues, 11. 1, 52-57, (in Polish).

Kircher, M., Roth, A., Adam, N. et al.: 2003, Remote sensing observation of mining induced subsidence by means of differential SAR-interferometry. In: IGARSS 2003. 2003 IEEE International Geoscience and Remote Sensing Symposium. Proceedings (IEEE Cat. No. 03CH37477), 1, 209-211. DOI: $10.1109 /$ IGARSS.2003.1293726

Kowalski, A.: 2020, Surface deformations in coal mining areas. Central Mining Institute, Katowice, (in Polish).

Kratzsch, H.: 1983, Mining Subsidence Engineering. Springer-Verlag, Berlin Heidelberg.

Krawczyk, A. and Grzybek, R.: 2018, An evaluation of processing InSAR Sentinel-1A/B data for correlation of mining subsidence with mining induced tremors in the Upper Silesian Coal Basin (Poland). E3S Web Conf 26:00003. DOI: 10.1051/e3sconf/20182600003

Ma, F., Sui, L., Ma, F. and Sui, L.: 2020, Investigation on mining subsidence based on Sentinel-1A data by SBAS-InSAR technology - Case study of Ningdong Coalfield, China. Earth Sci. Res. J., 24, 373-386. DOI: 10.15446/esrj.v24n3.90123

Milczarek, W.: 2019, Application of a small baseline subset time series method with atmospheric correction in monitoring results of mining activity on ground surface and in detecting isduced seismic events. Remote Sens., 11, 1008. DOI: 10.3390/rs11091008

Milczarek, W., Kopeć, A., Głąbicki, D. and Bugajska, N.: 2021, Induced seismic events-Distribution of ground surface displacements based on InSAR methods and Mogi and Yang models. Remote Sens., 13, 1451. DOI: $10.3390 / \mathrm{rs} 13081451$

Morishita, Y., Lazecky, M., Wright, T.J. et al.: 2020, LiCSBAS: An open-source InSAR time series analysis package integrated with the LiCSAR automated Sentinel-1 InSAR processor. Remote Sens., 12, 424. DOI: $10.3390 / \mathrm{rs} 12030424$

Ng, A.H.-M., Ge, L., Du, Z. et al.: 2017, Satellite radar interferometry for monitoring subsidence induced by longwall mining activity using Radarsat-2, Sentinel-1 and ALOS-2 data. Int. J. Appl. Earth Obs. Geoinf., 61, 92-103. DOI: 10.1016/j.jag.2017.05.009

Pawluszek-Filipiak, K. and Borkowski, A.: 2020a, Integration of DInSAR and SBAS techniques to determine mining-related deformations using Sentinel-1 data: The case study of Ryduttowy Mine in Poland. Remote Sens., 12, 242. DOI: $10.3390 / \mathrm{rs} 12020242$

Pawluszek-Filipiak, K. and Borkowski, A.: 2020b, Monitoring mining-induced subsidence by differential radar interferometry and persistent scatterer techniques. Eur. J. Remote Sens., 0, 1-13. DOI: $10.1080 / 22797254.2020 .1759455$ 
Pawłuszek-Filipiak, K. and Borkowski, A.: 2021, Mininginduced tremors in the light of deformations estimated by satellite SAR interferometry in the Upper Silesian Coal Basin, Poland. Procedia Comput. Sci., 181, 685692. DOI: 10.1016/j.procs.2021.01.219

Perski, Z.: 1998, Applicability of ERS-1 and ERS-2 InSAR for land subsidence monitoring in the Silesian coal mining region, Poland. Int. Arch. Photogramm. Remote Sens. Spat. Inf. Sci., 32, 555-558.

Perski, Z.: 1999, Surface subsidence of the Upper Silesian Coal Basin (Southern Poland) due to mining, date detected by satellite radar interferometry. Geological Review, 47, 171-174, (Polish).

Rudziński, Ł., Mirek, K. and Mirek, J.: 2019, Rapid ground deformation corresponding to a mining-induced seismic event followed by a massive collapse. Nat. Hazards, 96, 461-471.

DOI: $10.1007 / \mathrm{s} 11069-018-3552-0$

Sandwell, D., Mellors, R., Tong, X., Wei, M. and Wessel, P.: 2011, Open radar interferometry software for mapping surface deformation. Eos, Trans. Am. Geophys. Union, 92, 234. DOI: 10.1029/2011EO280002

Sen, A.T., Cesca, S., Bischoff, M., Meier, T. and Dahm, T.: 2013, Automated full moment tensor inversion of coal mining-induced seismicity. Geophys. J. Int., 195, 1267-1281. DOI: $10.1093 /$ gji/ggt300

Sopata, P., Stoch, T., Wójcik, A. and Mrocheń, D.: 2020, Land surface subsidence due to mining - induced tremors in the Upper Silesian Coal Basin (Poland) Case study. Remote Sens., 12, 3923.

DOI: $10.3390 / \mathrm{rs} 12233923$

Szaflucki, M., Malon, A. and Tymiński, M.: 2020, Balance of mineral resources in Poland as at 31 December 2019. Polish Geological Institute - National Reaserch Institute Warszawa, (in Polish).

Tong, X. and Schmidt, D.: 2016, Active movement of the Cascade landslide complex in Washington from a coherence-based InSAR time series method. Remote Sens. Environ., 186, 405-415.

DOI: $10.1016 /$ j.rse.2016.09.008

Wessel, P. and Smith, W.H.F.: 2013, Generic mapping tools: Improved version released. EOS Trans. AGU, 94, 409-10. DOI: 10.1002/2013EO450001

Yang, Z., Li, Z., Zhu, J., Yi, H., Hu, J. and Feng, G.: 2017, Deriving dynamic subsidence of coal mining areas using InSAR and logistic model. Remote Sens., 9, 125. DOI: $10.3390 /$ rs 9020125

Zhang, L., Ge, D., Guo, X., Liu, B., Li, M. and Wang, Y.: 2020, InSAR monitoring surface deformation induced by underground mining using Sentinel-1 images. Proc. International Association of Hydrological Sciences. Presented at the TISOLS: the Tenth International Symposium On Land Subsidence, Delft (Netherlands), 17-21 May 2021, Copernicus GmbH, 237-240. DOI: 10.5194/piahs-382-237-2020

Zorychta. A. and Burtan, Z.: 2008, Conditions and future direction for technological developments in the coal mining sector. Mineral Resources Management, 24, 19, (in Polish). 


\section{APPENDIX}

ascending no. 175

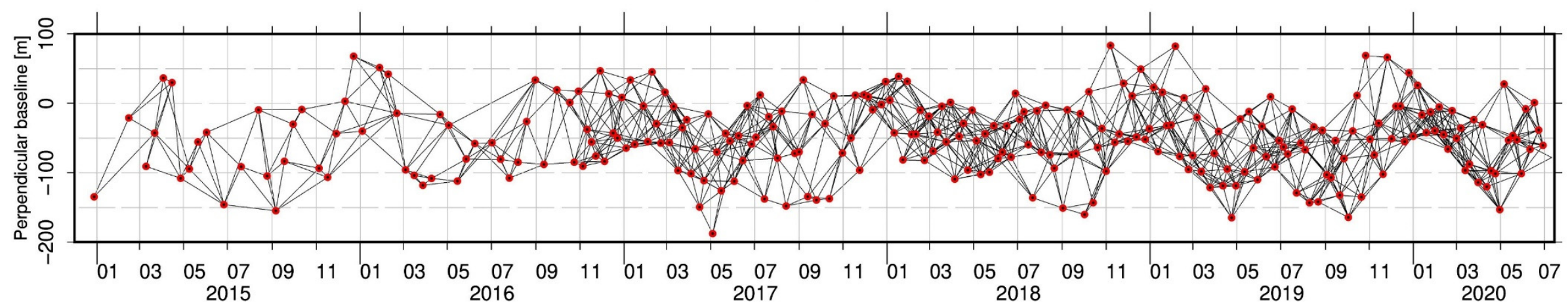

descending no. 51

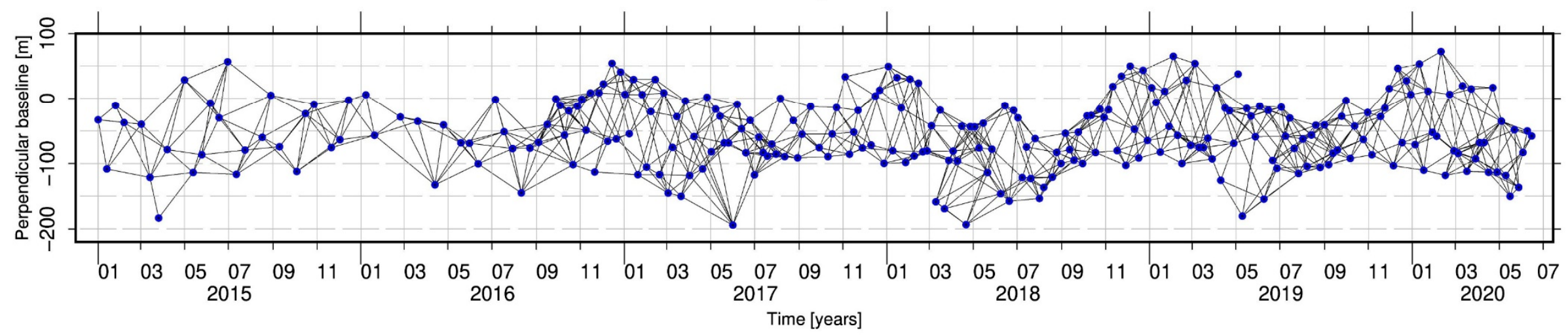

Appendix 1 Combinations of interferogram networks for the ascending (top) and descending (bottom) path. 